\title{
SELECTION IN MIXED COLONIES OF CEPAEA NEMORALIS AND CEPAEA HORTENSIS
}

\author{
M. A. CARTER * \\ Department of Zoology, University Museum, Oxford
}

\section{INTRODUCTION}

CAIN and Sheppard have shown (1954) that there is a correlation between the proportion of morphs in a population of $C$. nemoralis and the background of the habitat on which the snails occur. They have argued that this correlation is most likely to be due to selective visual predation, the most cryptic morph in any habitat being favoured. Clarke ( 1960 ) has found a comparable correlation in C. hortensis. As in $C$. nemoralis the most cryptic morph is at a high frequency but the crypsis is brought about in a different way, i.e. in woods (with dark uniform backgrounds) $C$. nemoralis has a high proportion of brown and pink unbanded morphs, whereas $C$. hortensis has a high proportion of banded yellows with fused bands, both species thus having a high proportion of effectively dark morphs.

Cain and Sheppard suggested that since the polymorphism was stable and old (Diver, 1940), there was some physiological advantage of the heterozygote maintaining it. However, since there were always rarer non-cryptic morphs present as well as cryptic ones, they considered the possibility of a frequency-dependent visual selective mechanism maintaining the polymorphism. In such a situation phenotypes would be at an advantage when rare. The kind of mechanism that might be acting is suggested by the works of Reighard (Igo8), De Ruiter (1953), and Tinbergen (1960) who showed that predators formed searching images for their prey. In the case of Cepaea the predator would form a searching image for the most common morph, which in the Oxford district would be the most cryptic. Thus the rarer non-cryptic morphs would be at an advantage. Cain and Sheppard could find no evidence that this was the case.

Clarke (1962a) in his analysis of Popham's data has shown, however, that frequency dependent visual selection can be effective in other species under some conditions. Later $(1962 b)$ he offered evidence that such frequency dependent visual selection, which he called apostatic selection, is important in determining morph frequencies in mixed colonies of $C$. nemoralis and hortensis. Lamotte (I95I, I959) has shown that there is no parallel variation in response to visual selection for crypsis in the two species, e.g. he found no significant correlation between the proportions of unbandeds in either species, but, as Clarke pointed out, the two species respond to visual selection in a similar way, but by different morphs. He therefore considered

* Present address: Department of Biological Sciences, College of Technology, Portsmouth. H 2 
it more reasonable to compare the proportions of classes of morphs with visually similar properties.

One of the comparisons that Clarke made was between the proportions of yellow nemoralis, and yellow effectively unbanded hortensis. This showed a significant overall positive correlation, e.g. the samples from woods contained a higher proportion of effectively dark shells than did the samples from open habitats. There was however, a significant negative correlation of yellow nemoralis and yellow effectively unbanded hortensis in samples taken from open habitats. Thus he suggested that visual selection for crypsis is important in both species but apostatic selection is also operating, the rarer species obtaining an advantage by being distinct from the more common one.

During the past three years I have collected samples from mixed colonies in a survey of both species on the Berkshire Downs. Using the methods of analysis given by Clarke $(1962 b)$ I have obtained results that conflict with his conclusions. These results are presented here with a discussion of Clarke's data and conclusions.

\section{METHODS}

\section{(i) Collecting}

Random samples were collected from mixed colonies of $C$. nemoralis and $C$. hortensis and, in certain cases from unmixed colonies nearby for comparison. All the samples come from the Berkshire Downs. Data from previous workers' samples taken from the Berkshire Downs (Clarke, 1962b, and unpublished), Salisbury Plain (Cain and Currey, 1963b) and from the Oxford district (Clarke, 1960, 1962b) have also been used.

\section{(ii) Scoring and classes of morphs considered}

Shells were scored for age, condition (live, dead, whole or predated), colour and banding (Cain and Sheppard, 1954; Cain and Currey, 1963; Clarke, 1960). Juveniles were not included in the score of a sample as it was not possible to tell which species they were. Samples with less than ten individuals of either species were not included in the analysis. The classes of morphs considered were those given by Clarke $(1962 b)$ and are shown in table 1 .

\section{(iii) Statistical tests}

The main test used was that given by Clarke (1962b).

\section{RESULTS}

(i) Distribution of mixed colonies of C. nemoralis and C. hortensis on the Berkshire Downs

$C$. nemoralis and $C$. hortensis occur widely over the Berkshire Downs (Carter, in preparation), although $C$. hortensis occurs only sporadically in the east, mostly in the dry valleys of the Chalk plateau. In the west this species is very common on the face of the escarpment to the 


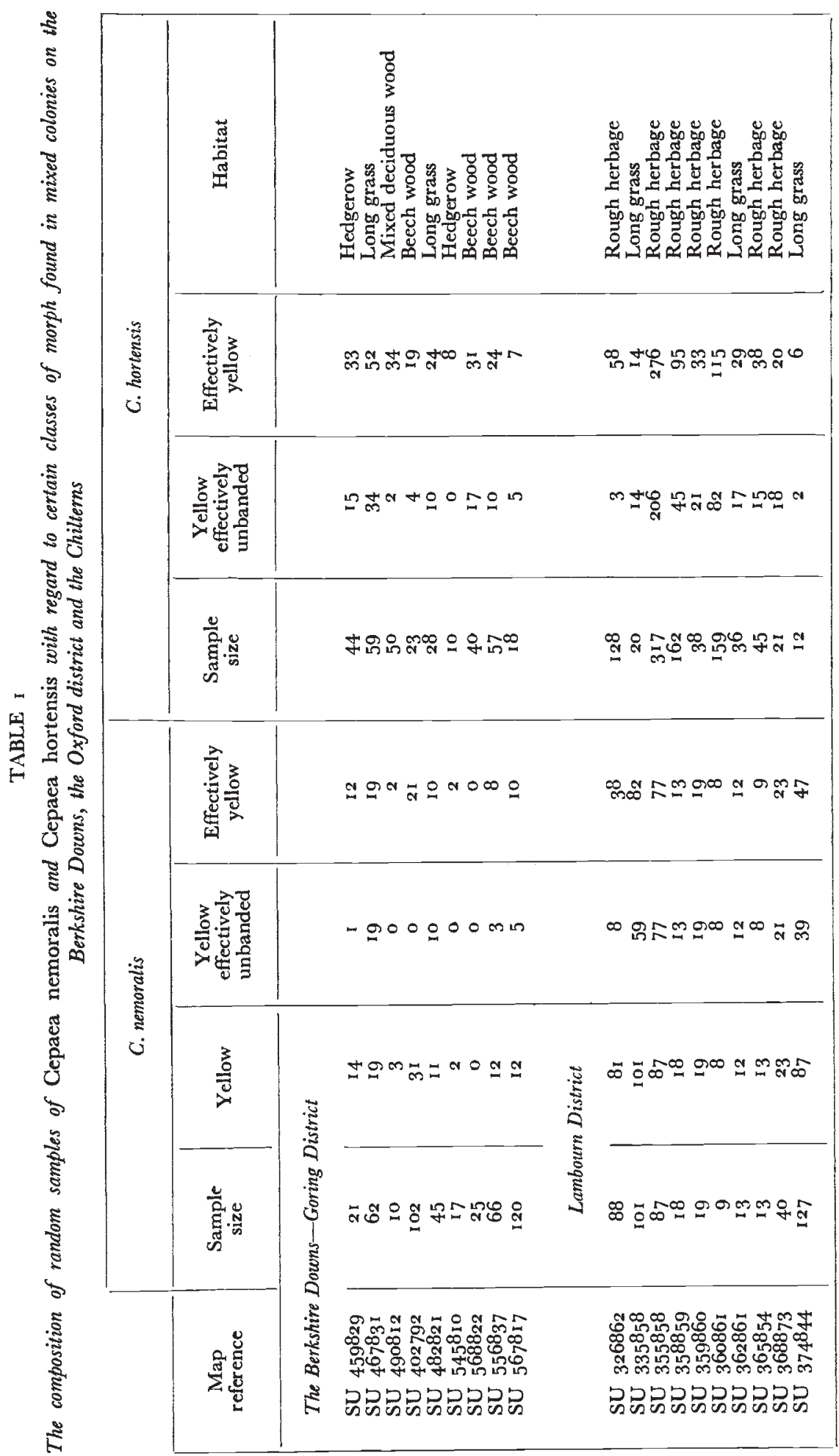




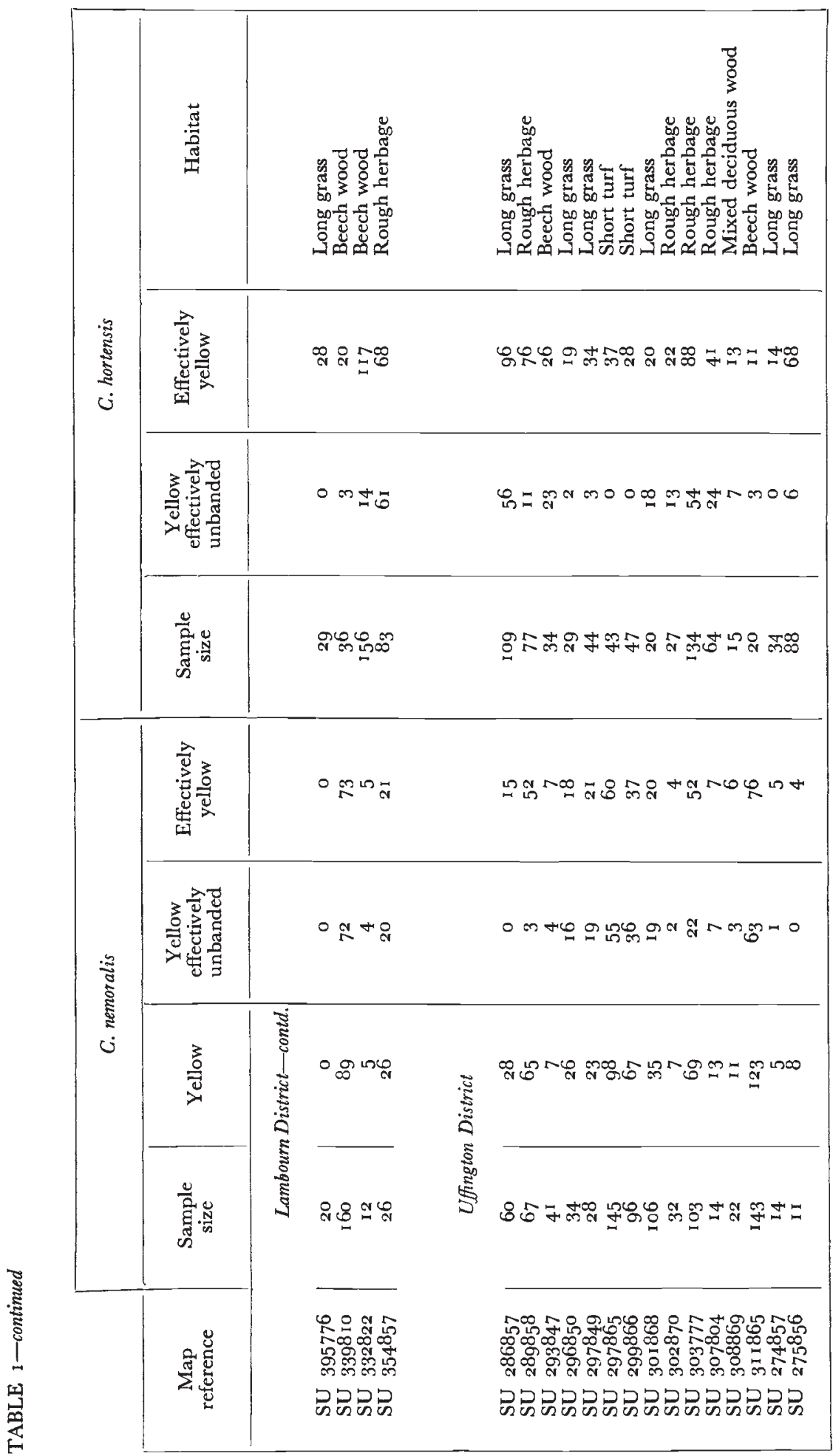




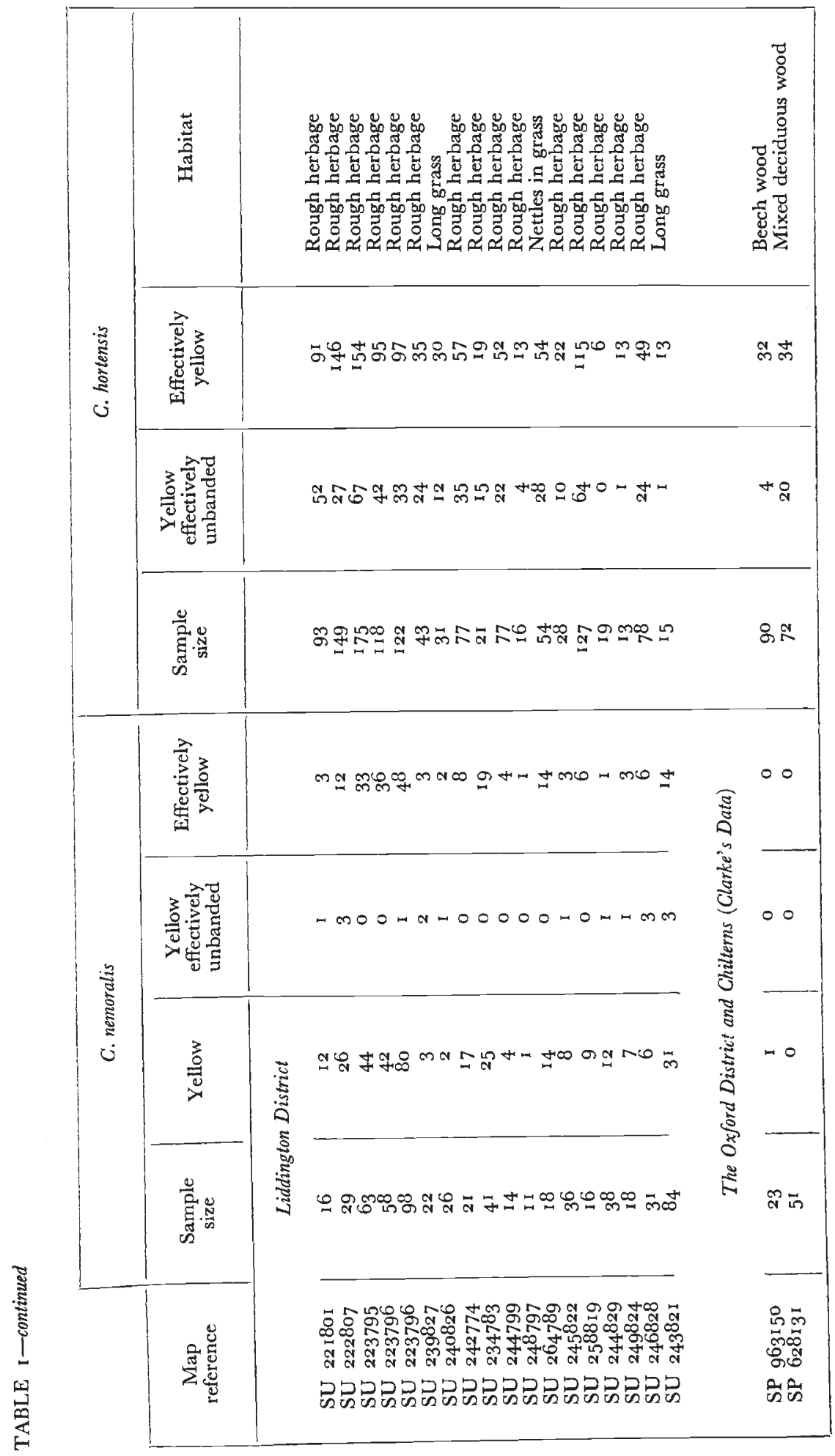




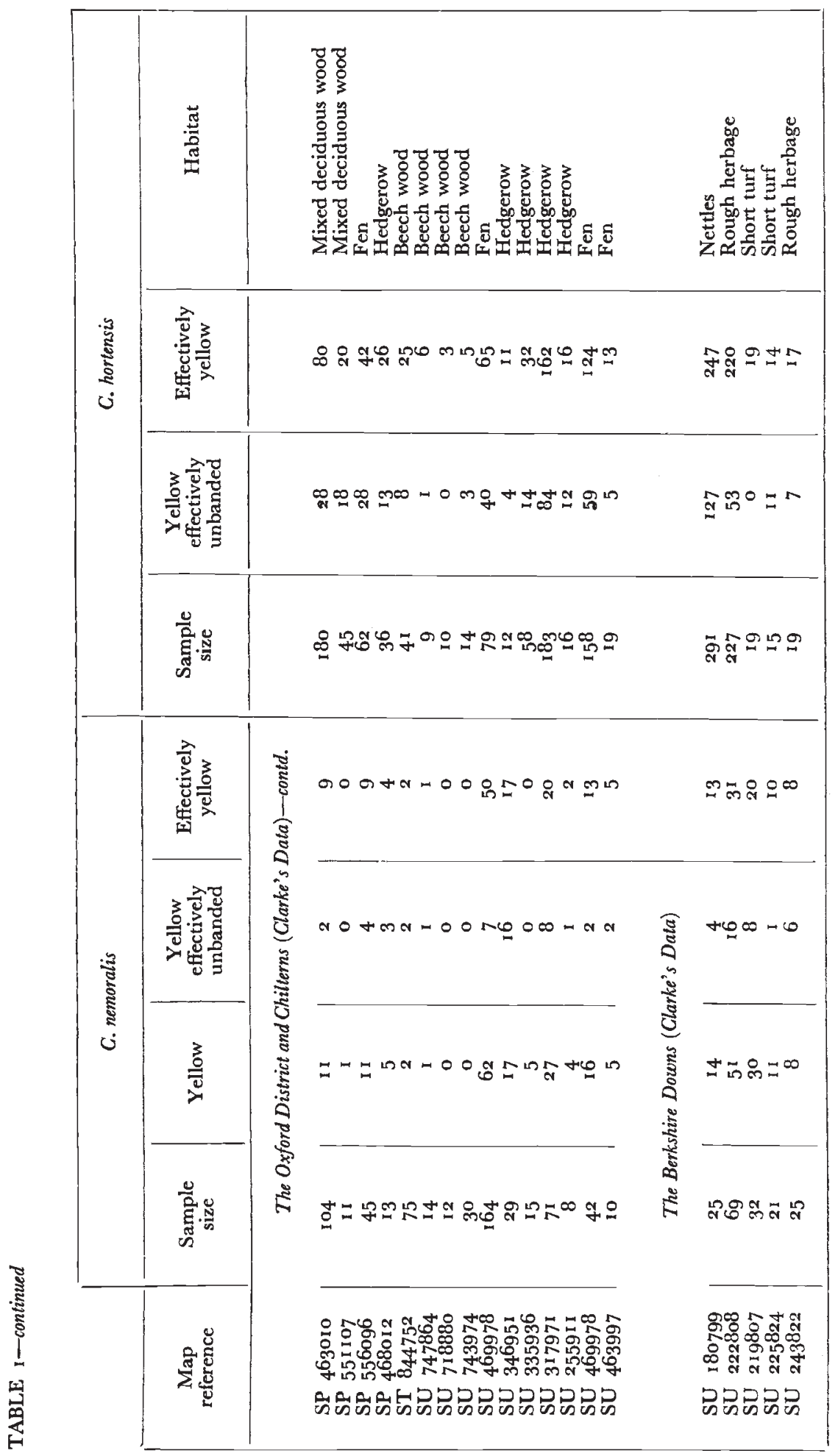




\begin{tabular}{|c|c|c|c|c|c|}
\hline \multirow{4}{*}{ ن } & 莺 & & 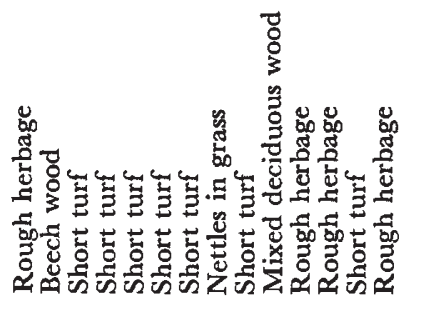 & & 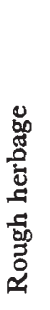 \\
\hline & 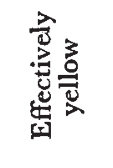 & & 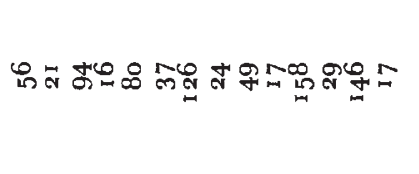 & & F \\
\hline & 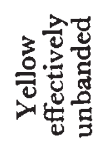 & & "ే-m+oழ & & बे \\
\hline & 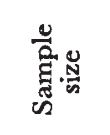 & & 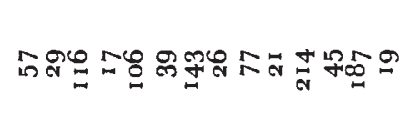 & & 욤 \\
\hline \multirow{6}{*}{ 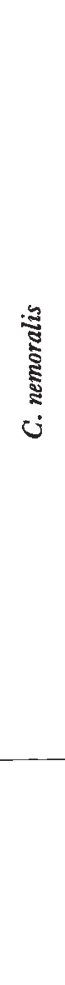 } & 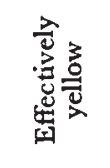 & \multirow{6}{*}{ 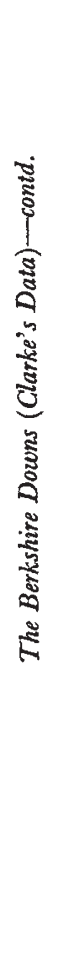 } & 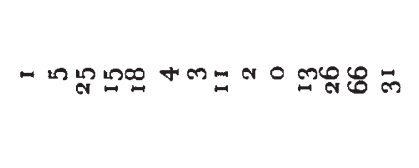 & & $m$ \\
\hline & 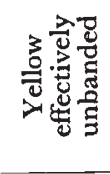 & & 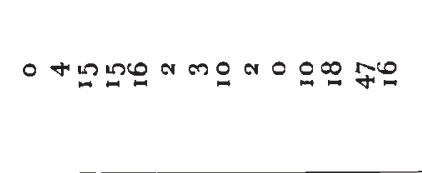 & & 0 \\
\hline & 言 & & No & \multirow{4}{*}{ 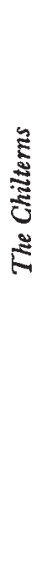 } & 0 \\
\hline & 苋芯 & & 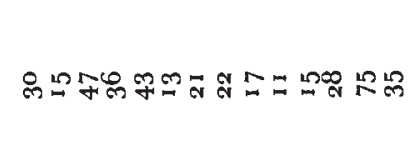 & & ణ \\
\hline & \multirow{2}{*}{ 空总 } & & 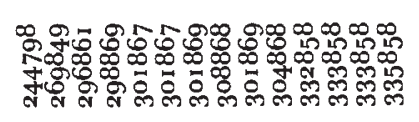 & & 索 \\
\hline & & & 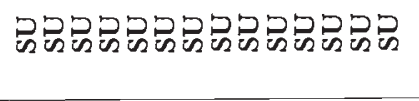 & & ? \\
\hline
\end{tabular}


north of the Chalk plateau. C. nemoralis occurs commonly over the high plateau. Mixed colonies of the two species occur in both woods and open habitats in the east of the region, but mostly in the open habitats in the west. The morph frequencies differ in both species in the different districts on the Berkshire Downs that I have defined (Carter, in preparation), but the limits of the districts are similar in both species.

Clarke $(1962 b)$ considered the situation in which visual selection for crypsis and visual apostatic selection were acting together. This situation might be true of the eastern districts of the Berkshire Downs where visual selection for crypsis is effective, but in the western districts, visual selection for crypsis is most ineffective and in each district there are area effects for different morphs in the two species. As visual predation is occurring in these latter districts it is possible that apostatic selection is effective in some or all of them. In this case it could, in the absence of selection for crypsis, produce quite different results with regard to the type of morph selected for from those it might effect in districts where the two selective forces interact. I have therefore analysed the results of samples from mixed colonies taken from the different districts separately. The districts are from east to west; Goring, Lambourn, Uffington and Liddington. I have only a few samples from the Goring district with sufficient numbers to allow me to do a detailed analysis of morph frequencies and therefore I shall consider them after I have discussed the results from other districts.

\section{(ii) The Lambourn district}

Cain and Currey (1963a) have shown that there is an area effect in C. nemoralis in this district although visual selection for crypsis is partially effective in woods in the south. The samples from these woods have a higher proportion of pink morphs than do adjacent open habitat samples but there are no differences in the frequencies of the effectively unbanded morphs which are at a high frequency in all habitats. I have confirmed these results (Carter, in preparation) and have shown that the area effect is extensive although visual selection is partially effective over the whole district for morphs not taking part in the area effect. There is a very wide scatter of morph frequencies in $C$. hortensis, but a comparison of the two southern wood samples with adjacent open habitat ones shows no morph frequency changes that would agree with the hypothesis of visual selection for crypsis. The open habitats are half a mile away from the woods, which is too great a distance for their similarity in morph frequencies to be explained by gene flow. There is no evidence of variation of morph frequency with habitat in the samples of this species taken from the main part of the district.

A comparison of the frequency of yellow $C$. nemoralis and yellow effectively unbanded $C$. hortensis in mixed colony samples shows a slight positive correlation if all such samples are included in the 
analysis $(\mathrm{P}<0.05>0 \cdot 02)$. This might be taken as evidence for visual selection for crypsis but the few samples from woods are from the south and should really be excluded from the analysis, as the selection pressures are probably rather different there from those in the main part of the district. If these and the nearby open habitat samples

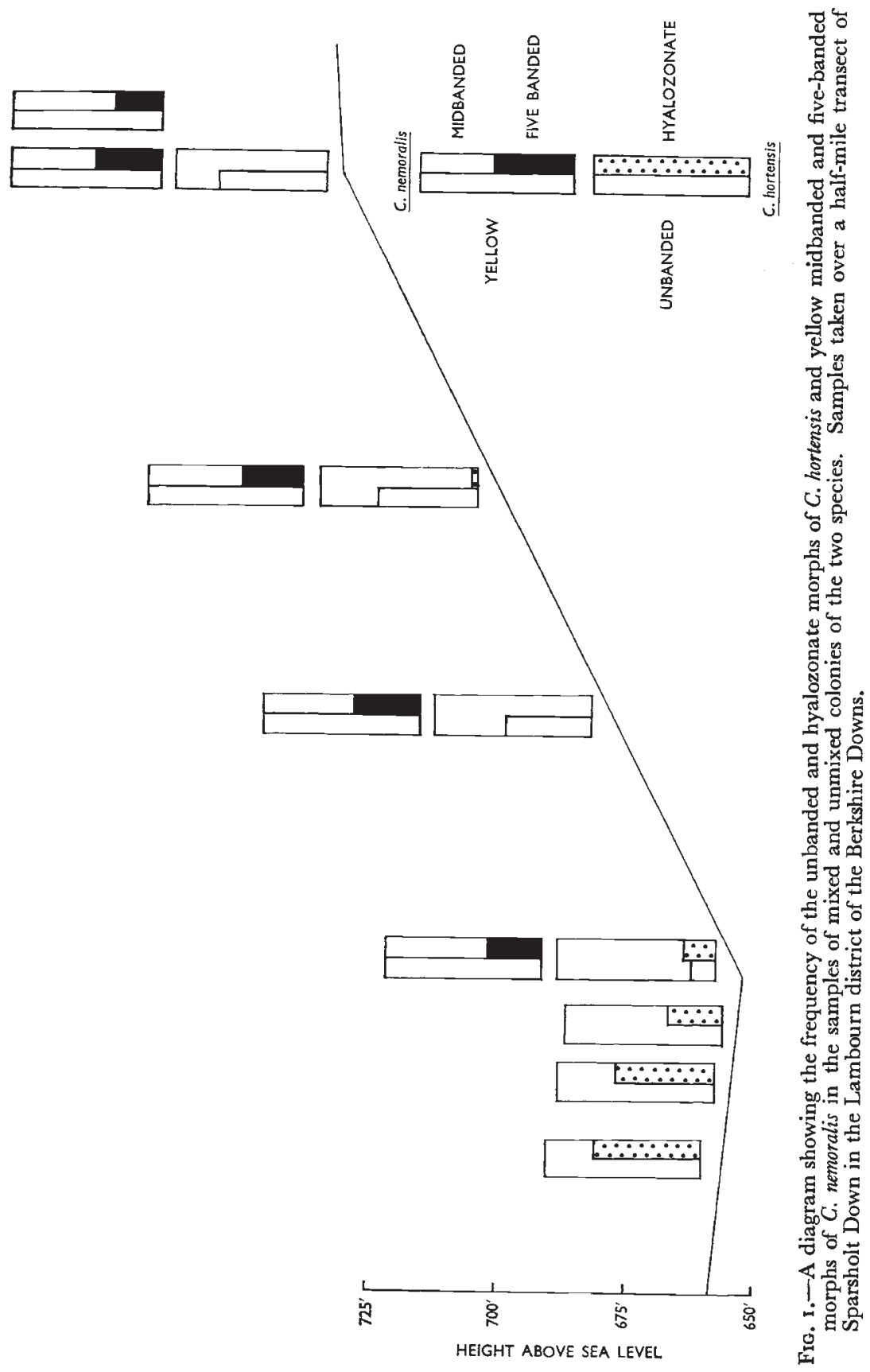


are removed, the overall correlation is not significant $\mathrm{P}<0.05$. There is no negative correlation within the group of samples from open habitats such as was found by Clarke in a similar analysis (1962b). Analyses of the data using the other methods given by Clarke (1962 $b$ ) give similar results to the above. There is therefore no evidence of apostatic selection in this district.

Fig. I shows a series of samples from mixed and unmixed colonies over a half a mile transect on Sparsholt Down. The lower series of histograms shows the proportions of unbanded and of hyalozonate morphs in $C$. hortensis and the upper series the proportions of yellow and midbanded morphs in $C$. nemoralis. The hyalozonate and unbanded morphs in hortensis are visually similar. On the hypothesis of visual apostatic selection one might expect that the combined frequencies of these two morphs would affect or be affected by the frequency of visually similar morphs of $C$. nemoralis in mixed colonies of the two species. Fig. I shows that there is no marked difference in the frequency of visually similar morphs between mixed and unmixed colonies in either species. This would argue against visual apostatic selection. It is also interesting that whereas the frequency of all the C. nemoralis morphs remains more or less constant, the unbanded and hyalozonate morphs in $C$. hortensis shows progressive and opposite changes with distance, indicating that selection is acting independently on the two species.

\section{(iii) The Uffington district}

A comparison of the frequency of yellow $C$. nemoralis and yellow effectively unbanded $C$. hortensis in mixed colony samples seems to suggest that apostatic selection is effective in this district, since there is a significant negative correlation within the group of samples from the open habitats $\left(\mathrm{P}<\mathrm{O}^{\circ} \mathrm{OI}\right)$. There is also a significant negative correlation between the proportion of yellow effectively unbandeds in both species $(\mathrm{P}<0.05>0 \cdot 02)$. There is no evidence that visual selection for crypsis is effective on either species. These results are different from those found by Clarke $(1962 b)$ and it is possible that apostatic selection is operating here in the absence of visual selection for crypsis. There is however some evidence that it is not. Most of the samples from mixed colonies have been taken from the Chalk escarpment. C. hortensis is common at the bottom of the slope but extends up it. C. nemoralis on the other hand is common on the high plateau, and although it is found on the escarpment it is rare at the bottom. There are area effects in both species in this district, but in mixed colonies the characteristic morph frequencies of the area effects seem to break down. Fig. 2 shows the frequency of the yellow unbanded morph in $C$. hortensis in samples taken from mixed colonies on the escarpment at Uffington. These are the only effectively unbanded morphs present in these samples. The unbanded morph frequency is higher in the samples from the bottom of the slope than 


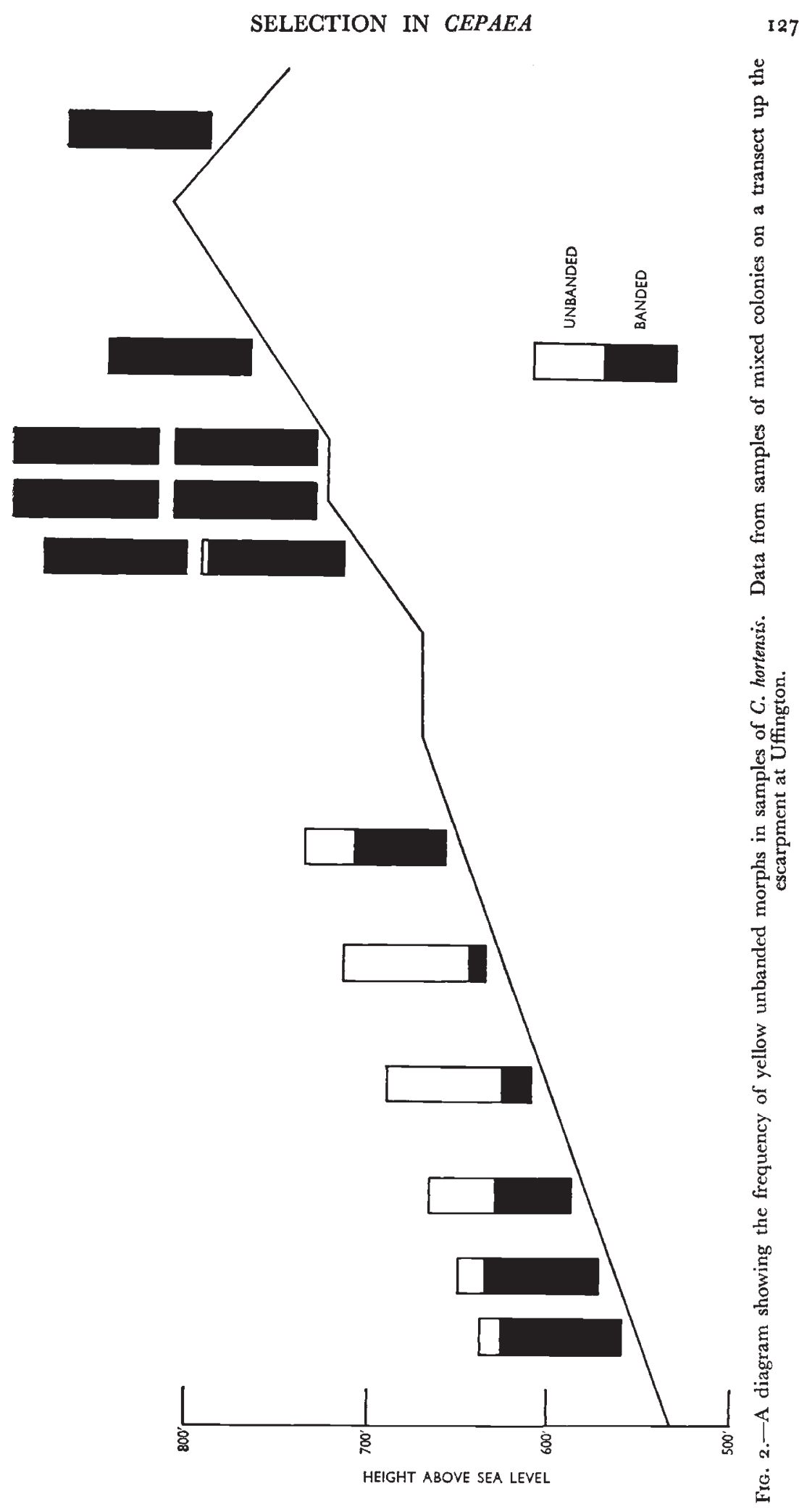


in those at the top. The morph frequency increases from the bottom of the slope then falls off rapidly, the morph being absent in the top five samples. Comparison of the frequencies of the various $C$. nemoralis morphs shows that the samples that have the highest frequency of dark colour morphs (browns and pinks) are those in which the proportion of yellow unbanded $C$. hortensis is highest, and also, where there is a high frequency of yellow effectively unbanded $C$. nemoralis the frequency of yellow unbanded $C$. hortensis is lowest. These results support the hypothesis that apostatic selection is effective, but fig. 3 shows the frequency of yellow unbanded $C$. hortensis in samples taken from unmixed colonies at Woolstone, half a mile west of Uffington. The changes in the proportion of the yellow unbanded morph are very similar to those in the mixed colonies at Uffington, although the morph does not reach such high frequencies as it does there.

Unfortunately I have not been able to obtain a parallel series of samples from unmixed colonies of $C$. nemoralis. There are three samples from apparently unmixed colonies at Uffington which have very similar morph frequencies to the nearby mixed colonies, but this could be due to gene flow since the colonies are less than ioo m. apart and the size of the panmictic unit has been shown to be approximately $60 \mathrm{~m}$. (Lamotte, I95 I; Murray, i 963).

The two series at Uffington and Woolstone are half a mile apart. This is much too great a distance to allow gene flow to cause any similarity of morph frequencies. It seems likely that there is some selective pressure bringing about a change in the frequency of unbanded $C$. hortensis regardless of the occurrence of $C$. nemoralis. It is possible that the $C$. nemoralis morph frequencies are determined apostaticly, i.e. where $C$. hortensis is common, at the bottom of the slope, the rarer $C$. nemoralis's morph frequencies may be determined by apostatic selection. Where $C$. hortensis is rare at the top of the escarpment the morph frequencies of $C$. nemoralis are determined by some selective factor causing area effects. There are, however, regular changes in the frequencies of brown $C$. nemoralis up the escarpment at Uffington and in other series of samples some distance away, so that it is possible that the changes in morph frequency of this species are not due to apostasis.

\section{(iv) The Liddington district}

In the comparison of the frequencies of yellow $C$. nemoralis and yellow effectively unbanded $C$. hortensis it was found that samples taken from the east and west of this district were heterogeneous. The samples were separated into two groups on their geographical position. Those from the east showed a random scatter in the above comparison, but the open habitat samples from the west showed a negative correlation $(\mathrm{P}<0.05>0.02)$. No correlation with any environmental variable could be found that might account for this negative relationship. There is no heterogeneity in the comparison of the frequency of yellow 


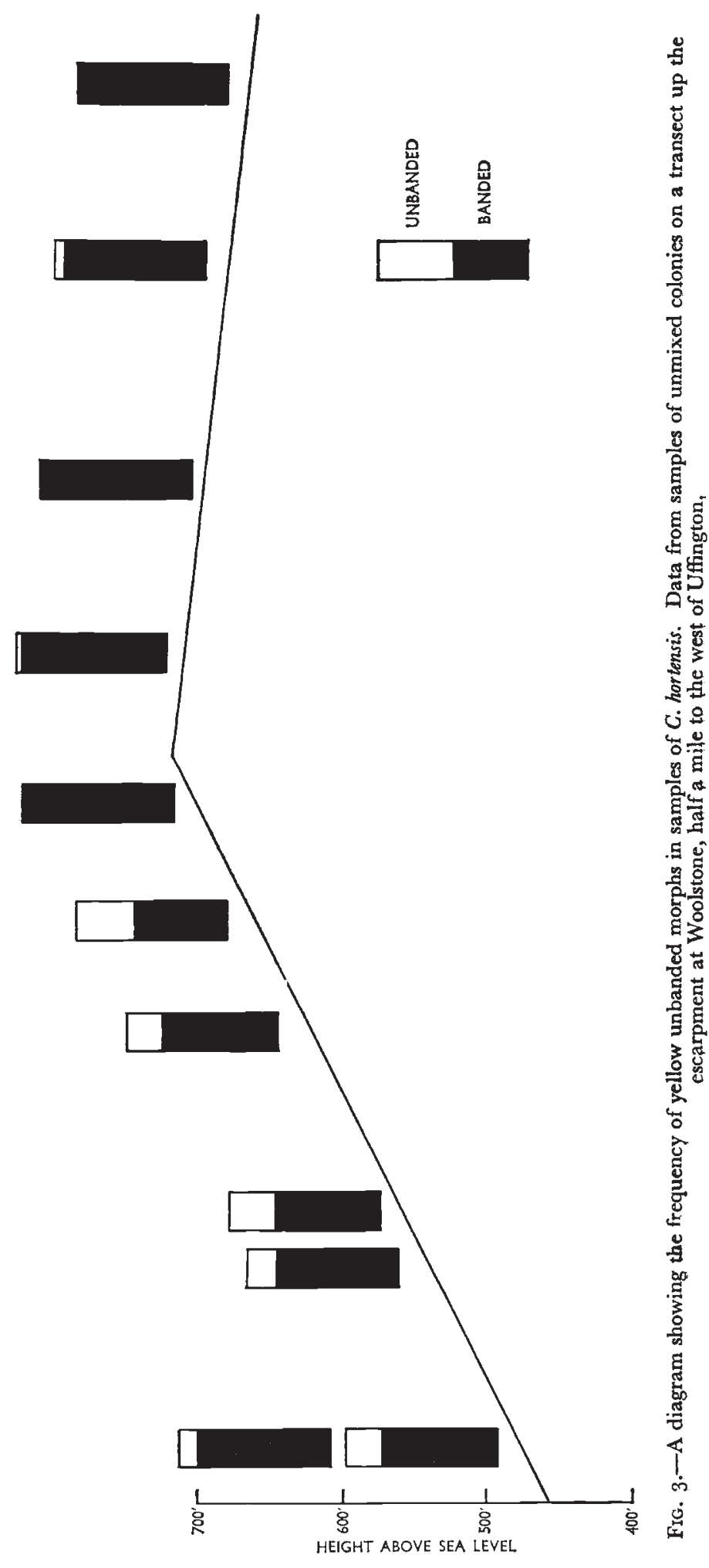


effectively unbanded morphs in the two species. This group of morphs is at a low frequency in C. nemoralis over the whole district. There is no significant correlation within the open habitat class in this comparison $(P>0.05)$. There are no overall positive correlations when samples from both woods and open habitats are included in either of the above analyses and therefore there is no evidence that visual selection for crypsis is effective. The evidence in favour of apostasis is conflicting, but it is possible that it is acting in the west.

\section{(v) Salisbury Plain}

Cain and Currey $(1963 b)$ collected samples of both species from part of Salisbury Plain and they have shown that there is no evidence that visual selection is effective in either species. They sampled several mixed colonies and pointed out that as there was no evidence for visual selection for crypsis they would not expect apostatic selection to be effective, nor could they find any evidence that it was. A comparison of the frequencies of yellow $C$. nemoralis and yellow effectively unbanded $C$. hortensis gives no evidence of any correlation. The proportion of yellow effectively unbanded $C$. hortensis is low in all samples regardless of the frequency of yellow $C$. nemoralis.

\section{(vi) Comparison of morph frequencies in mixed and adjacent unmixed colonies of the two species}

Some of the changes in the frequency of the light morphs of $C$. nemoralis and $C$. hortensis between mixed and nearby unmixed colonies can be used to investigate apostasis. In general, if the frequencies of a given class of morphs in each species are more dissimilar in mixed colonies than they are between adjacent unmixed colonies, this is evidence in favour of apostasis.

The method of comparison is as follows (fig. 4). The proportions of yellow nemoralis and yellow effectively unbanded hortensis are plotted along the abscissa and ordinate. The co-ordinates of greatest similarity of these two frequencies fall along the diagonal joining the two sets of co-ordinates (o per cent., o per cent.) and ( Ioo per cent., Ioo per cent.). Lines drawn parallel to this diagonal represent equal degrees of similarity along their length, but the further they are away from the main diagonal, the more the degree of similarity that they represent decreases. The morph frequencies in the two unmixed colonies adjacent to each mixed colony are treated as if coming from a mixed colony (open circles in fig. 4). The mixed colonies are plotted as filled-in circles and each one is joined to its respective open circle representing the combined unmixed colonies. The morph frequencies in the mixed colony are more or less alike than those in the adjacent unmixed colonies depending on whether the filled-in circle is nearer to, or further away from the main diagonal than the open circle.

There are 18 samples from mixed colonies on the Berkshire Downs with sufficient numbers of shells and with unmixed colonies near 
enough to carry out such an analysis. The distance between the colonies to be compared is never less than 200 yards or more than 800 yards. In 12 of the 18 comparisons the yellow $C$. nemoralis and yellow effectively unbanded $C$. hortensis frequencies are more alike in

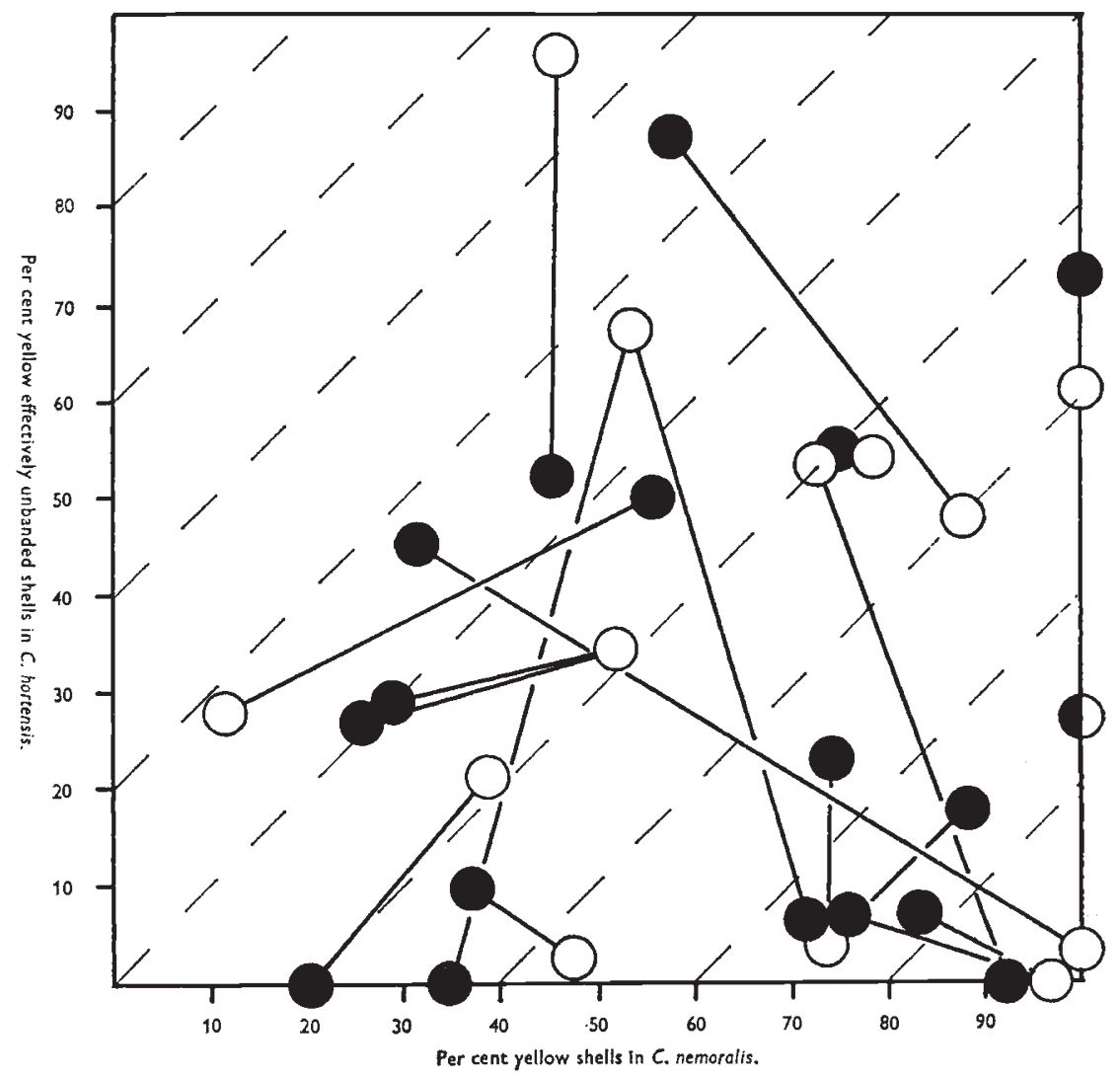

FIG. 4.-A scatter diagram comparing the proportions of yellow " effectively unbanded" shells in $C$. hortensis and yellow shells in $C$. nemoralis in samples taken from mixed and unmixed colonies on the Berkshire Downs. Mixed colonies are represented by filled-in circles and unmixed colonies by open circles. Adjacent mixed and unmixed colonies are joined.

the mixed than in the unmixed colonies. In five mixed colonies the frequencies are less alike, and in one comparison the frequencies are the same in the mixed and unmixed samples. In the absence of apostatic selection or any other interaction between the two species, there should be equal numbers of mixed colonies which are more alike and less alike than their respective unmixed colonies. The result obtained is not significantly different from this expectation $\chi_{(1)}{ }^{2}=2 \cdot 65, P>0 \cdot I$.

\section{DISCUSSION}

Clarke $(1962 b)$ argued from his data that visual selection for crypsis and apostasis were interacting. However, some of his samples were 
taken from the Uffington and Liddington districts. The results of the work presented here show that visual selection for crypsis is not effective in either of these districts, and therefore samples taken from them should not be included in any analysis of the interaction of the two forms of selection. Clarke, as he did not know of the occurrence of area effects, also collected samples widely both on and off the chalk in his (1960) demonstration of morph frequency variation with habitat in C. hortensis. Detailed surveys of snail populations on the chalk (Cain and Currey, I963a and $b$; Arnold, in preparation; Carter, in preparation) have shown that visual selection is ineffective over most of such regions investigated. Isolated samples from different chalk regions should not, therefore, be considered together, in any analysis of the effects of visual selection. It is known that visual selection for crypsis is effective in C. nemoralis in the Oxford district (Cain and Sheppard, I954) and along the northern edge of the Chilterns (Arnold, in preparation). Fortunately Clarke ( 1960$)$ also sampled these districts

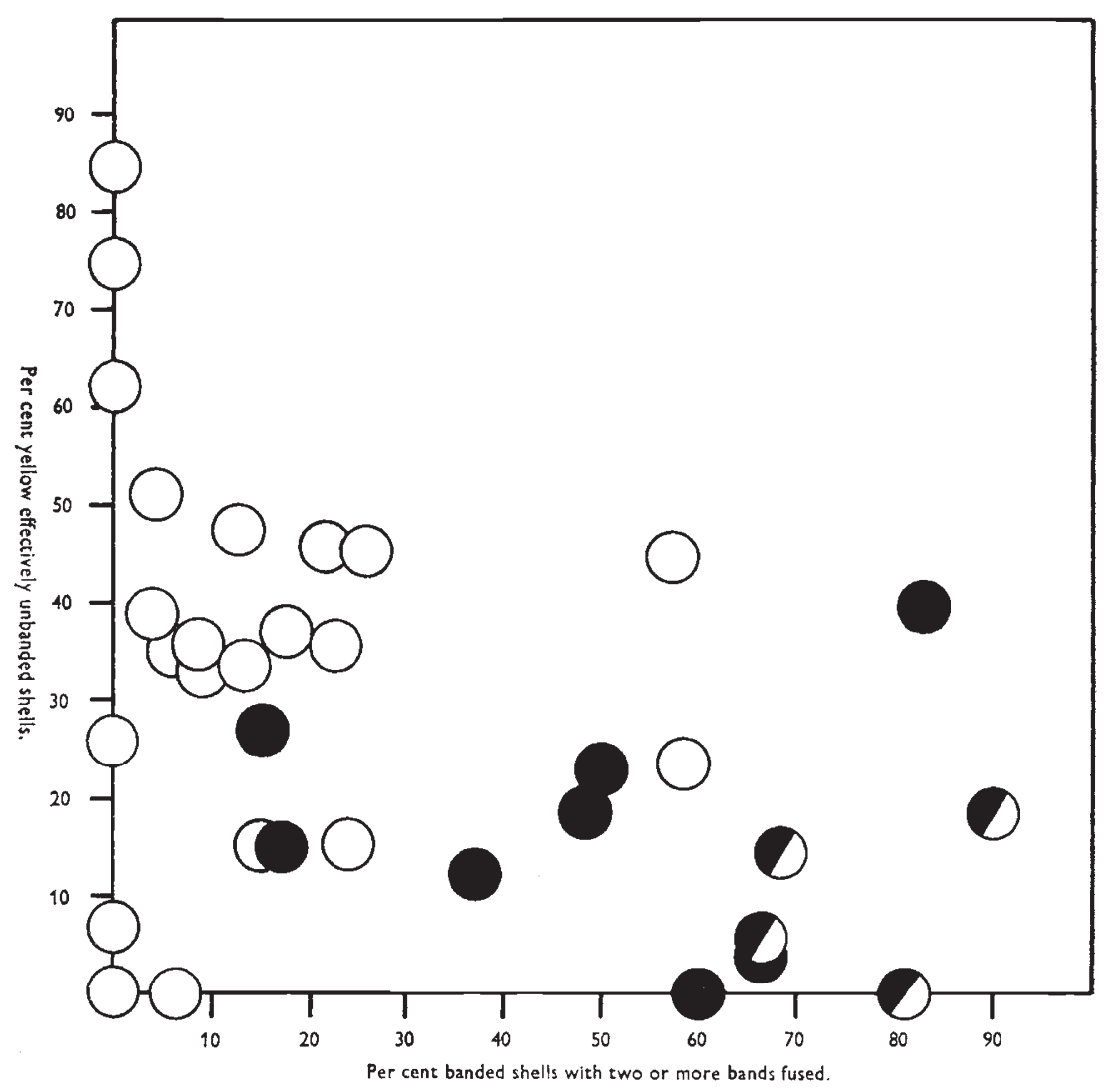

FIg "5.-A scatter diagram for C., hortensis showing the relation between the percentage of "yellow effectively unbanded" shells, the percentage of banded shells with fused bands and the nature of the habitat. The data are from samples collected by Clarke (I960) in the vicinity of Oxford. Samples from woods, black circles; samples from fens, half black circles; samples from open habitats, open circles. 
in detail for $C$. hortensis, although he combined the results with the others that he obtained. Since it is possible that his data was heterogeneous I have reanalysed those for the Oxford district and Chilterns alone.

Fig. 5 (Clarke's data) shows the proportion of yellow effectively unbanded morphs plotted against the proportion of banded morphs with some bands fused in $C$. hortensis. The ordinate is slightly different from that given by Clarke ( 1960 ) since I have included all those yellow morphs that are effectively unbanded, i.e. unbanded, hyalozonates and five-bandeds with the upper two bands missing, while Clarke used only yellow unbandeds. Clarke independently came to the conclusion that these morphs could be grouped in his $1962 b$ paper. There is a separation between the samples from the darker and more uniform habitats (woods and ivy) and the lighter and more heterogeneous habitats (hedgerows and rough herbage). This separation is significant on both axes $(\mathbf{P}<0.02>0.01$ in both cases). Since the measurements along both axes are independent the $\chi^{2}$ s can be summed. This gives a significant separation between the two groups of habitats with $\mathbf{P}=\mathrm{o} \cdot \mathrm{OI}$.

Inspection of Clarke's data ( 1960 ) shows that those samples which contain a low proportion of banded morphs with fusions have relatively high proportions of pinks and/or brown morphs. Since the proportion of banded morphs with fusions is being used as a measure of the proportion of effectively dark shells (Clarke, I960), it is reasonable to include both pinks and browns with the yellow five-banded-fused. This does decrease the independence of the measurement of the effectively dark morphs from that of the yellow effectively unbandeds but the measurements are not the inverse of each other since the yellow five-banded-unfused are not included in the calculation of either proportion. Fig. 6 shows that using this method there is a very clear separation of the samples from the darker and lighter habitats. Both the woodland and more open habitat samples form closer groups than in fig. 5. If a line is drawn dividing the samples into two equal-sized groups, at right angles to the slope of the scatter, and the separation between the woodland samples falling below the line and the open habitat samples falling above the line is tested it is found to be significant with $\mathrm{P}<0.00 \mathrm{I}$. Thus although several of the more openhabitat samples may contain a high proportion of five-banded morphs with fusions out of all the five-bandeds, the proportion of the fivebandeds in each sample as a whole is small, and therefore the darkening effect is not very great. In woods, however, the proportion of the fivebandeds is higher and consequently if most of these show fusion of bands the proportion of effectively dark morphs is high. In those woodland samples with a low frequency of yellows, the darkening effect is brought about by pinks and browns, most of which are unbanded, as well as by the fusion of bands in the yellows.

Clarke's data indicates that visual selection for crypsis is effective 
in $C$. hortensis in the Oxford district and the Chilterns as he claimed, but the effectiveness is better shown by grouping morphs as in fig. 6 of the present paper. It is also clear from his data ( 1960$)$ and my own (Carter, in preparation) that the species is more polymorphic for colour in these districts and other lowland districts in the south of England than on the high Chalk downland in Central England that has so far been investigated.

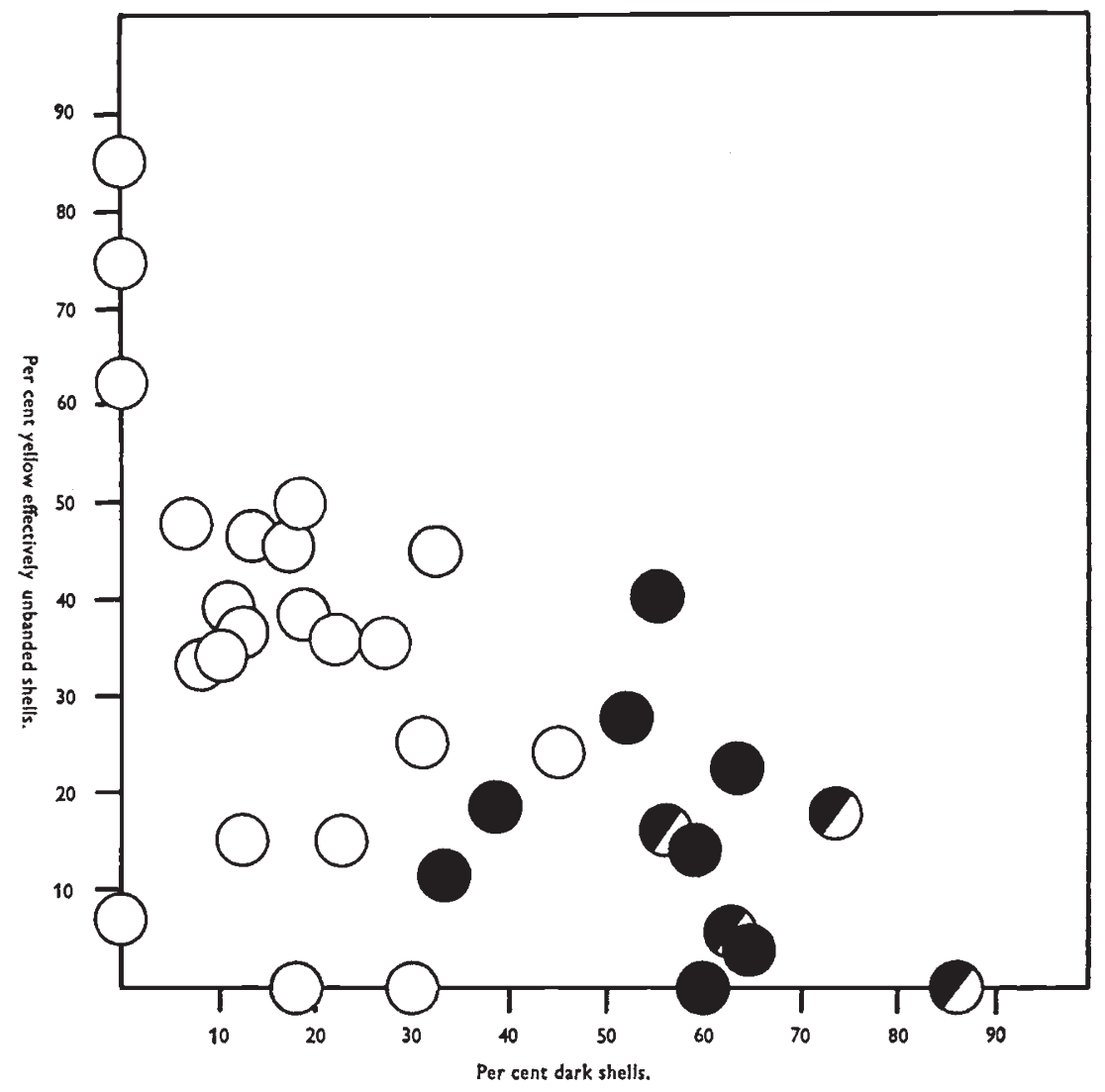

Fig. 6.-A scatter diagram for $C$. hortensis showing the relation between the percentage of yellow "effectively unbanded" shells and "effectively dark" shells. Data from samples collected by Clarke ( 1960$)$ in the vicinity of Oxford. Symbols as in fig. 5 .

Since visual selection for crypsis is effective in both species in the Oxford district and the Chilterns, Clarke's data from mixed colonies from these two districts can be considered together. (I have tested for heterogeneity between samples from the two districts, and there is none.) Fig. 7 makes a comparison between the proportion of yellow $C$. nemoralis and yellow effectively unbanded $C$. hortensis from Clarke's data and is therefore his fig. $4(1962 b)$ with samples taken from the Chalk removed. Fig. 8 shows the samples in fig. 7 plus a few that I have obtained from the Goring district of the Berkshire Downs. I 


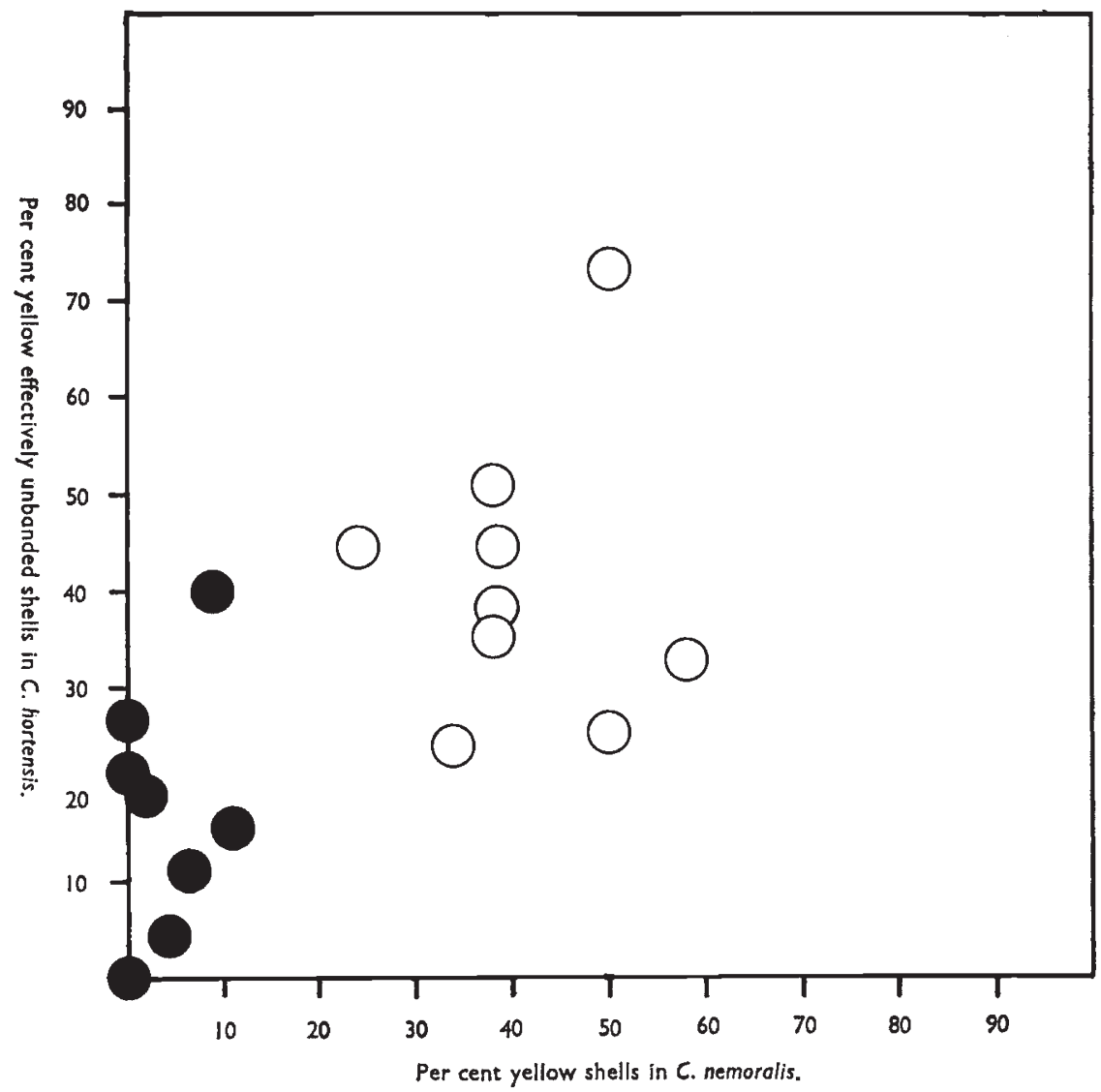

FIG. 7.-A scatter diagram showing the relation between the percentage of yellow " effectively unbanded" shells in $C$. hortensis and the percentage of yellow shells in $C$. nemoralis. Data from samples of mixed colonies in the vicinity of Oxford (Clarke, I962). Symbols as in fig. 5 .

have shown previously (Carter, I965a) that visual selection for crypsis is effective in both species in this district, and have therefore felt justified, since the samples show the same trends, in lumping them with Clarke's.

It is evident in both figures that there is an overall positive correlation of the samples. In fig. 8 this is significant with $\mathrm{P}<0.00 \mathrm{I}$. There is a separation between samples from woods and those from more open habitats on both axes ( $\mathrm{P}<\mathrm{O} \cdot \mathrm{OI}$ in both cases). Since the measurements along each axis are independent of each other the $\chi^{2} \mathrm{~s}$ can be summed giving a probability of $\mathrm{P}<0 \cdot 00 \mathrm{I}$. These results confirm that visual selection for crypsis is effective on both species in mixed colonies in these three districts.

There is no heterogeneity of the samples from different districts within the open habitat class in figs. 7 and 8 and thus these samples can be tested for a within-class correlation. With the test given by Clarke $(1962 b)$ there is found to be a non-significant positive correla- 
tion $(r=0 \cdot 136, \mathrm{P}>0 \cdot \mathrm{I})$ between the frequency of yellow $C$. nemoralis and yellow effectively unbanded $C$. hortensis. This is a quite different result from that obtained by Clarke who found that there was a significant negative correlation for the data from his samples, which included both those in fig. 7 and his samples from Liddington and Uffington, and other districts on the Chalk (his fig. 4).

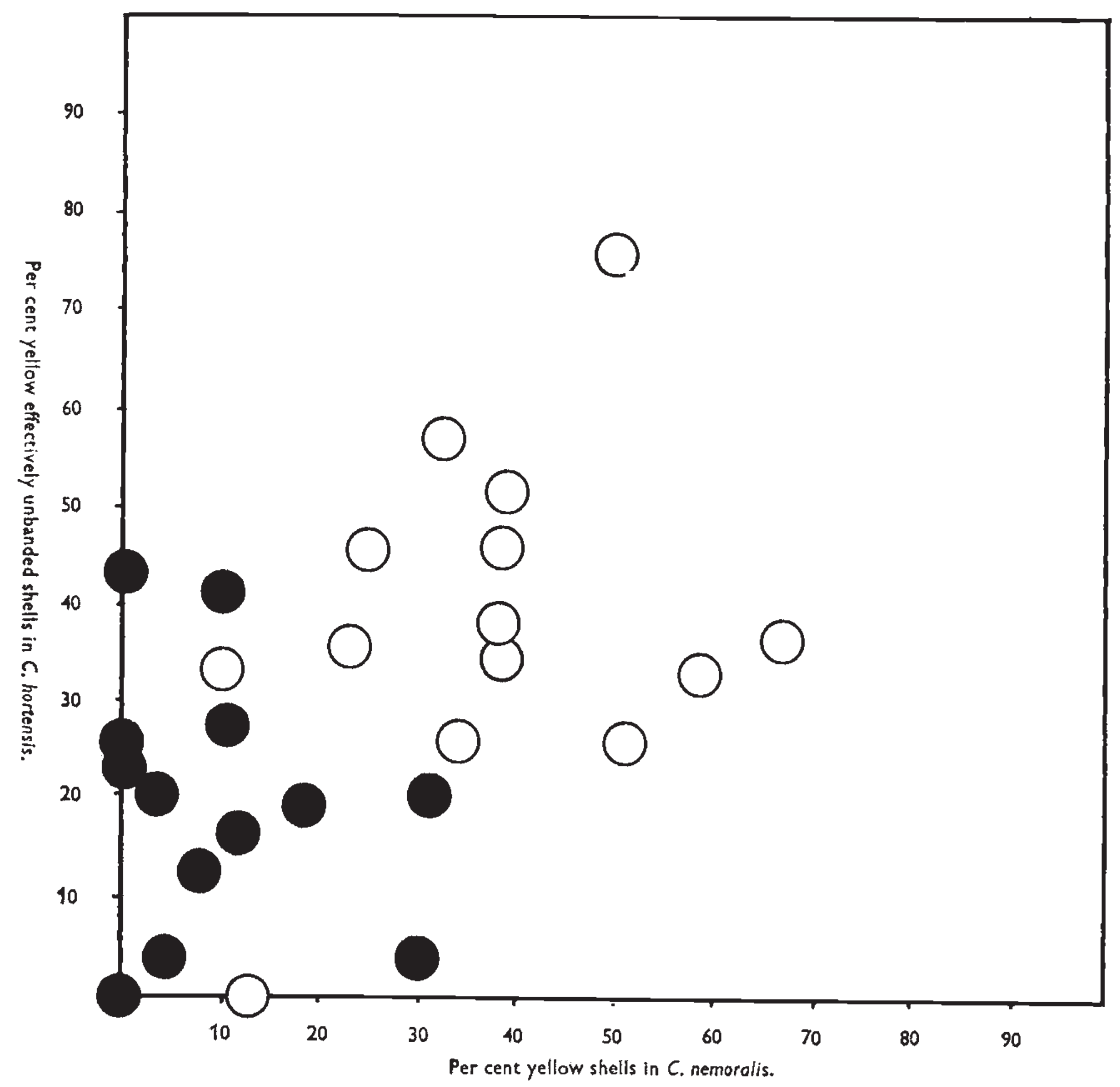

Fig. 8.-A scatter diagram showing the relation between the percentage of yellow " effectively unbanded" shells in C. hortensis and the percentage of yellow shells in C. nemoralis. Data from samples of mixed colonies in the vicinity of Oxford (Clarke, 1962) and a few samples of mixed colonies from the Goring district of the Berkshire Downs. Symbols as in fig. 5 .

A similar test on the samples from woods in fig. 8 gives a nonsignificant negative correlation $\left(r=-0^{\prime} \mathrm{I}, \mathrm{P}>0 \cdot \mathrm{I}\right)$ as was found by Clarke $(\mathrm{r} 962 b)$.

Fig. 9 gives a comparison of the effectively yellow morphs in both species from the three districts where visual selection is effective. There is a significant separation between the samples from woods and more open habitats $\left(\mathrm{P}<\mathrm{O}^{\circ} \mathrm{OI}\right.$ on both axes), and there is an overall positive correlation by the medial test $(\mathrm{P}<0 \cdot 05)$. A similar positive correlation was found by Clarke $(1962 b)$ who therefore suggested that 
although apostatic selection was effective within habitat classes (from his fig. 4) there was overall selection in mixed colonies for crypsis. The positive correlation is the only one that I have obtained in all similar tests for four sets of data and confirms that it is only in the Oxford district, the Chilterns and the Goring district that visual selection for crypsis is effective in both species in mixed colonies.

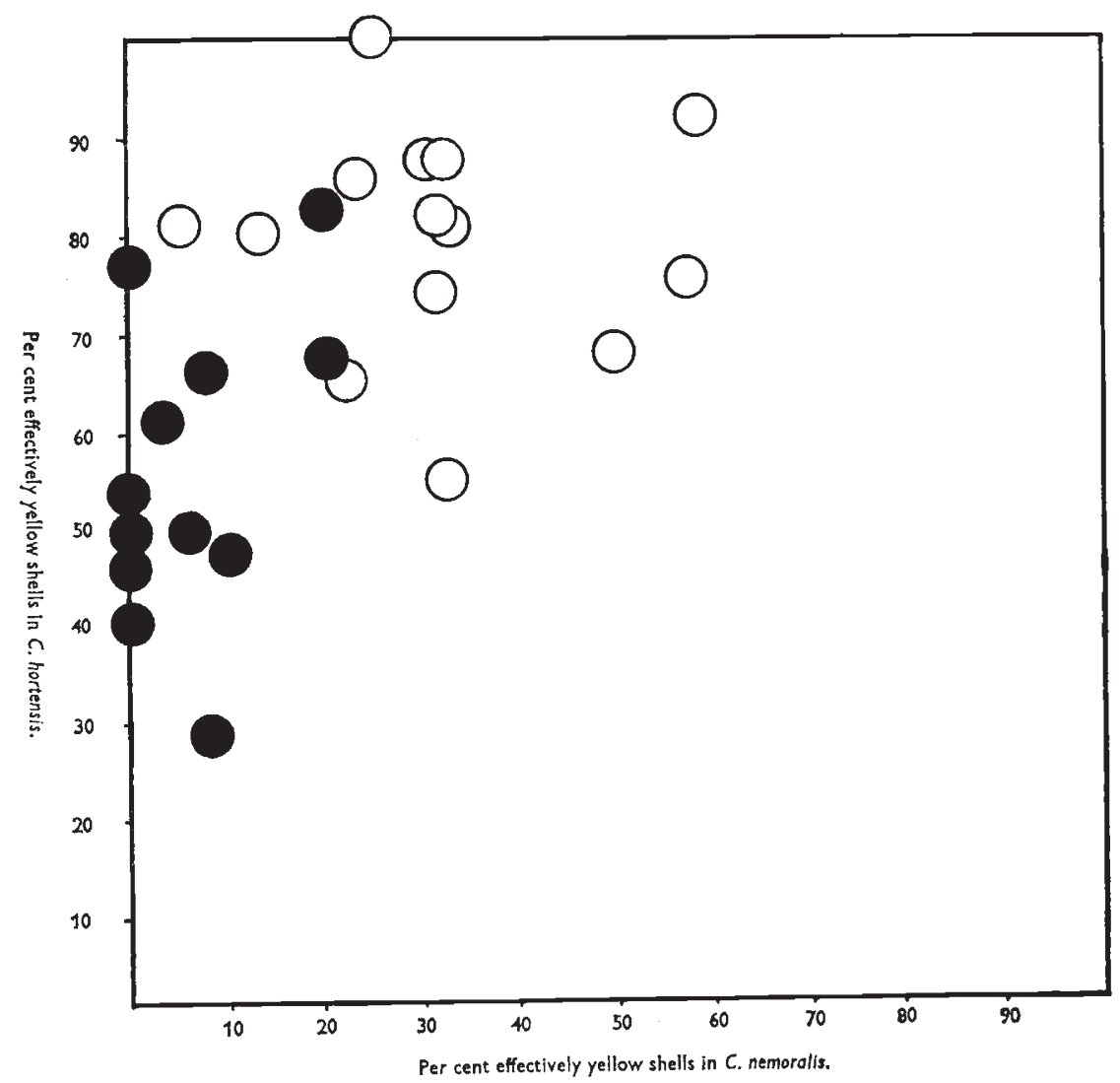

FIG. 9.-A scatter diagram showing the relation between "effectively yellow" shells in $C$. hortensis and $C$. nemoralis. Data from samples shown in fig. 13. Symbols as in fig. 5 .

\section{CONCLUSIONS}

It is clear that the data collected by Clarke which he used in support of his hypothesis of apostatic selection are heterogeneous. He

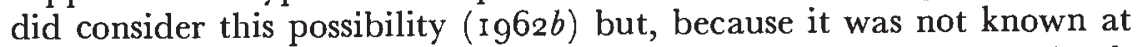
that time that area effects occurred extensively on chalk downland, he suggested that any such heterogeneity was unlikely. He did, however, point out that his evidence was not conclusive.

It is the collections from Chalk downland at Uffington and Liddington, in particular those from the open habitats in these districts, that are the main contributions to the negative correlation that he 
obtained. Visual selection for crypsis is ineffective in these districts and the evidence for apostatic selection is questionable. Over two other districts on the Chalk there is no evidence for either apostatic or cryptic selection and therefore only the three districts where visual selection for crypsis is effective remain to be considered in the investigation of the interaction of visual selection for apostasis and crypsis. The data presented above concerning these three districts does not give any significant evidence of an interaction between $C$. nemoralis and $C$. hortensis which would support the hypothesis of apostatic selection. Although there is no significant positive correlation within each habitat class, which might be expected if both species were responding to visual selection for crypsis, there are several factors mitigating against finding such a correlation. The samples have been taken from three districts, which, although adjacent, cover a large area, and it is to be expected that selective pressures other than visual selection will differ in many of the colonies. Thus there will be a more or less broad scatter of morph frequencies even within similar habitats. There must also be considerable variation of the background within habitat classes (Cain and Currey, r $63^{a}$ ).

The separation between the samples from woods and those from the more open habitats and the overall positive correlation between samples, in the above three districts, do support the hypothesis that visual selection is favouring the most cryptic morphs in both species in any habitat. In those districts where visual selection for crypsis is ineffective the evidence is inconclusive, but it seems likely that there is some non-visual selective pressure determining morph frequencies independently in both species. It therefore follows that the hypothesis of apostatic selection in Capaea has yet to be substantiated.

\section{SUMMARY}

I. In order to investigate whether apostatic selection and visual selection for crypsis interact (Clarke, $1962 b$ ), districts in which visual selection for crypsis occurs should be considered separately from those where it is ineffective or only partly effective.

2. Analysis of three districts in which visual selection for crypsis is effective in both species, and in which there are mixed colonies, gives no significant evidence of apostatic selection. The most cryptic morph in either species is favoured in any given habitat.

3. Analysis of four districts where visual selection is ineffective, or only partly effective, although visual predation does occur, gives no concrete evidence in favour of apostatic selection in Cepaea.

Acknowledgments.-I am very grateful to Professor A. J. Cain, who has generously given his help and encouragement at every stage of this work. Dr. J. D. Currey, Dr. B. C. Clarke, Dr. R. W. Arnold, and Mr. C. Graham have all been generous 
in their assistance, discussion and criticism. This work was carried out during the tenure of a Nature Conservancy Research studentship at the Department of Zoology, Oxford. I am very grateful to Professor J. W. S. Pringle, F.R.S., for the help and facilities he has provided.

\section{REFERENCES}

CAIN, A. J., AND SHEPPARD, P. M. 1954. Natural selection in Cepaea. Genetics, 39, 89-116.

CAIn, A. J., ANd currey, J. D. 1963a. Area effects in Cepaea. Phil. Trans. Roy. Soc. B., Vol. $246, \mathrm{I}-8 \mathrm{I}$.

CAIN, A. J., AND CURREY, J. D. 19636 . Area effects in Cepaea on the Larkhill Artillery Ranges, Salisbury Plain. F. Linn. Soc. (Zool.), 45, No. 303, 1-15.

CARTER, M. A. Area effects and visual selection in Cepaea nemoralis and Cepaea hortensis. In preparation.

CLARKE, B. C. 1960. Divergent effects of natural selection on two closely related polymorphic snails. Heredity, $14,423-443$.

CLARKE, B. C. 1962a. Balanced polymorphism and diversity of sympatric species. In Taxonomy and Geography, ed. D. Nichols. Syst. Ass. Pub., No. 4.

CLARKE, B. C. 1962b. Natural selection in mixed populations of two polymorphic snails. Heredity, 17,3 19-345.

DIVER, c. 1940. The problem of closely related species living in the same area. In New Systematics, ed. J. Huxley. London, Oxford University Press.

DE RUITER, L. 1952. Some experiments on the camouflage of stick caterpillars. Behaviour, 4, 222-232.

LAMOTTE, M. 1951. Recherches sur la structure génétique des populations naturelles de Cepaea nemoralis (L). Bull. Biol. Suppl., 35, 1-239.

LAmотте, м. 1959. Polymorphism of natural populations of Cepaea nemoralis. Cold Spr. Harb. Symp. Quant. Biol., 24, 65-86.

MURRAY, J. J. 1962. Movement and mortality in a colony of Cepaea nemoralis. Thesis, Oxford University.

REIGHARD, J. 1908. An experimental field study of warning colouration in coral reef fishes. Publ. Carneg. Instn., ro3, 257-325. 